\title{
OPPORTUNITIES, RELATIONAL EMBEDDEDNESS AND NETWORK \\ STRUCTURE
}

\author{
Ulf Andersson
}

Uppsala University, Dept. of Business Studies

Desireé Blankenburg Holm

Uppsala University, Dept. of Business Studies

Martin Johanson

Uppsala University, Dept. of Business Studies

P. O. Box 513, 75120 Uppsala Sweden

Phone: +46 18 4711613; Fax: +46 18 4716810; e-mail: martin.johanson@fek.uu.se

\begin{abstract}
Network structures and relational characteristics have become increasingly prevalent in the study of how firms find and exploit market and technological opportunities. Some scholars claim that a large number of relationships with a low degree of relational embeddedness facilitate a firm's possibilities to gather new knowledge; others stress a high degree of embeddedness between the firm and its counterparts in order to absorb the new knowledge. The same bi-polarity can be seen when network structures are considered; certain scholars favor open structures while others favor closed network structures. The fact that each firm has restrictions in terms of resources highlights the question of how configurations of networks and relationships influence firms' possibilities to find and exploit opportunities. In this paper, we utilize different strands of theories about network structure and relationship characteristics to develop an understanding of how they should be configured in order to facilitate a firm's search for opportunities.
\end{abstract}

Keywords: Opportunities, Relational Embeddedness, Network Structure 


\title{
OPPORTUNITIES, RELATIONAL EMBEDDEDNESS AND NETWORK
}

\author{
STRUCTURE
}

\section{INTRODUCTION}

The thesis of this paper is that the characteristics of the business network surrounding the firm have a profound impact on how the firm finds and exploits opportunities. Characteristics of networks and relations between network actors have been increasingly researched during the last decades (see e.g. Dyer and Chu 2000; Grabher 1993; Granovetter 1985, 1992; Gulati 1998, 1999; Gulatiet al. 2000; Halinen and Törnroos 1998; Håkansson and Snehota 1995; Kogut 2000; McEvily and Zaheer 1999; Rowley et al. 2000; Uzzi 1996, 1997; Zukin and Di Maggio 1990). In parallel, a wide and strong tradition of research has emerged on the nature of opportunity, especially among entrepreneurship researchers, (see e.g. Ardichvili et al. 2003; Eckhardt and Shane 2003; Shane 2000). We aim to combine these two traditions and seek to develop a model for analyzing the relation between different types of opportunities and different types of relationships and networks. Entrepreneurial behavior and social networks have previously been explored (Ardichvili et al. 2003; Ellis 2000; Jack and Anderson 2002; Kenney and Goe 2004; Simsek et al. 2003). These studies have observed that there seems to be a relation between finding an opportunity and the characteristics of the social network, but to our knowledge there are no studies investigating the character of relationships and network configurations and how it influences the firm's way of finding and exploiting opportunities. This chapter aims to fill this void.

We begin by highlighting the questions that this chapter tries to answer. After that follows a discussion where we define the opportunity concept and distinguish two activities in the opportunity-process, finding and exploiting opportunities. Thereafter, we propose that different types of knowledge tend to have different influences on how the firm finds and exploits opportunities, depending on the nature of its relationships and networks. The subsequent section deals with the concept of relational embeddedness, before we discuss open and closed network structures. Based on that discussion, we distinguish four situations characterized by various degrees of relational embeddedness and different network closure. Finally, the chapter concludes with managerial suggestions for finding and exploiting opportunities, given different degrees of relationship embeddedness and network structures that depend on the type of knowledge.

\section{KEY CONSIDERATIONS}

In our attempt to conceptualize how opportunities are found and exploited in different relationships and network settings, we identify four key considerations, from which the discussion begins. First, the characteristics of the firm and its network structure constitute the framework for its performance and since both finding and exploiting opportunities is contingent on the firm's behavior, the relationships and network are both a possibility and a constraint. The network structure is discussed in terms of open and closed networks (Coleman 1990) and we focus on the flow of knowledge and how firms can assimilate, reflect and compare the knowledge received. We build the analysis on the notions of relational embeddedness and open and closed networks. Zukin and DiMaggio (1990) classify embeddedness into four types but three are sufficient here: cognitive, cultural and political. These are often merged into relational embeddedness, which primarily concerns the qualitative aspects and the nature of relationships.

Second, we do not believe that all relationships and networks foster a variety of opportunities; instead it seems likely to expect that the type of opportunity found is dependent on the nature of the firm's relationships and the network structure. We make a distinction between market opportunities and technological opportunities, where market opportunity refers to the exchange of resources and technological opportunities are concerned with how firms combine resources. 
Third, we discuss what type of knowledge is likely to be the source of the opportunity. This discussion builds on findings made primarily by social network scholars, but also on results produced by the Industrial Marketing and Purchasing Group (Ford et al. 2003; Håkansson 1982). One important aspect of knowledge is whether the opportunity is based on new or existing knowledge. New knowledge implies that the firm does not know about the character and nature of the opportunity. Existing knowledge, on the other hand, is either the firm's own knowledge, which it is already using, or what they know is being used by other firms in the network. The other aspect of knowledge concerns whether it can be codified or not. This is important, because as relationships and networks are supposed to provide opportunities, the flow of knowledge in the network has an impact on how firms find opportunities. In general, we expect codified knowledge to be transferred more easily in the network than non-codified knowledge.

Fourth, and finally, once opportunities are found, the firm can decide to exploit them, but also, in this case, relationships and networks surrounding the firm have an impact on how the fruits of the opportunities are divided between the firms in the network. We make a distinction between the likeliness that some or a few firms in the network can earn income or if the benefits produced by the opportunities exploited are more evenly shared between a large number of firms.

\section{OPPORTUNITY}

Opportunity is the focus of this chapter. It refers to new ways of using resources, both internally and externally. New ways, which are more efficient, profitable or produce more value for the actors involved than the existing ways of using the resources. Eckhardt and Shane (2003, p. 336) define opportunities as situations in which new ways of using resources - through exchange or combination - can be introduced by transforming the existing ends and/or means. New ways imply that an opportunity for the enterprises involved has a high degree of originality in itself (Casson 1982; Choi and Shephard 2004). Finding opportunities is contingent on the fact that knowledge is imperfectly distributed among different actors in the economy (Hayek 1945), which means that opportunity is a subjective and perceptual concept, based on what the individuals know and perceive. Burt (1992b) has a similar starting point as he relates an actor's opportunity to his social capital, which in turn creates a competitive advantage. Each actor has a network of contacts in the [competitive] arena. Certain actors are connected to certain others, trusting certain others, obligated to support certain others, dependent on exchange with certain others (p.57). It then follows that there is no such thing as an objective opportunity, which is waiting to be found by any firm. Nor is any firm able to discover or recognize all opportunities. Instead, we assume that a firm's competitive advantage is based on its capability to find and exploit opportunities in a network. Two well-known economists help to divide the new ways of using resources into two types of opportunities:

First, there are market opportunities, which refer to exchange of resources between at least two actors. Kirzner $(1973,1992,1997)$ discusses entrepreneurial behavior in a market process characterized by disequilibrium. A driving factor in the market process is firms' capability to be alert to discover new ways of exchanging resources and new counterparts in the market. Kirzner makes a distinction between known ignorance and unknown ignorance. Finding market opportunities based on known ignorance implies that the firm can identify and specify what they are searching for, that is, it is based on existing knowledge. However, Kirzner also means that sometimes firms find market opportunities based on unknowable, that is, completely new knowledge. It is the finding of market opportunities based on new knowledge that drives the market process, according to Kirzner (1997).

Second, there are also technological opportunities, which can be viewed as new ways of combining resources without necessarily exchanging the new combination of resources with other actors. Technological opportunities correspond well to four of the five loci, which Schumpeter (1934) suggests are sources for change: creation of new products or services, discovery of new raw materials, new methods of production and new ways of organizing. The fifth locus refers to new geographical markets, which fall under the definition of market opportunities. 
Finding opportunities is accomplished through the execution of activities like search, exploration, discovery and recognition (March 1991), which means that finding an opportunity can be more or less planned, and thus appear after a more or less deliberate process. Exploiting opportunities involves activities like assimilation, absorption, deployment, implementation and utilization and it is thus a question of doing business with other actors and/or utilizing technologies. From the above, it follows that market and technological opportunities have to be found before they can be properly exploited. Opportunity implies finding something new and incorporating it into something which already exists, which means that there is need for fit (Ardichvili et al. 2003) between the opportunity and the firm's existing relationships and network, that is, the new knowledge, represented by the opportunity, must be able to be absorbed in the prevailing knowledge structure.

Dispersed knowledge is a prerequisite for the existence of opportunities, but dispersed knowledge also implies that firms learn. Since opportunities are new ways of using resources, the degree of novelty of the opportunities has an impact on how firms are able both to find and to exploit them. Finding opportunities is thus related to the firm's prior experience (Shane 2000) while the decision to exploit opportunities is more likely to be made when the firm perceives that it has knowledge about the new way of using resources (Choi and Shepherd 2004). The need for fit between opportunities and structure is thus relevant both for finding and exploiting opportunities. In furthering our understanding on how the firm can optimize the search and exploitation of opportunities, we have reason to focus on structural issues in terms of relationships and networks.

\section{RELATIONAL EMBEDDEDNESS}

One notion that is often put forward when discussing relationships and networks is relational embeddedness. Being embedded in a social context has been observed to create opportunities, and even sometimes to be a prerequisite for finding any opportunities (Burt 1992a; Ellis 2000; Jack and Anderson 2002). Much of our reasoning around embeddedness goes back to Granovetter's (1985) seminal article, where his stand was that economic behavior is not an autonomous activity, which is performed in isolation from institutions, technology, political or cultural conditions and the social context.

The point of departure for relational embeddedness is that a relationship between actors has several dimensions and that several types of activities are simultaneously performed. However, dimensions and activities are not isolated from each other. Instead, the embeddedness concept implies that they are interdependent. Consequently, strong interdependence between these dimensions means a high degree of embeddedness.

In this chapter, we focus on three specific dimensions of relationships: social relations, exchange of resources, and combination of resources. Thus, we assume that exchange between two firms in a relationship (economic action in Granovetter's terminology (ibid.)) can be more or less embedded in a technological structure, where the firms combine resources and invest and adapt their resources towards the counterpart, and that this exchange is more or less embedded in a set of social relations. We define relational embeddedness as the interdependence between social relations, exchange of resources, and combination of resources in the relationship. The reason for this definition is twofold. First, we assume that it is in line with Granovetter's (1985) ideas and, second, it seems consistent with the definition of opportunity. Thus, a high degree of embeddedness is a result of a high interdependence between how, when and why two actors exchange resources and how and what types of resources the actors combine in the relationship. In this case, the business performed in the relationship is embedded in the two actors' technological structure and social relations.

This means that market opportunities are more or less embedded in a technological structure and a set of social relations. When firms try to find and exploit market opportunities they have to consider both social relations and technological issues (see Figure 1). On the other hand, technological opportunities are embedded in an exchange structure and a set of social relations. The way firms 
exchange resources and handle social relations will consequently influence the process of finding and exploiting technological opportunities.

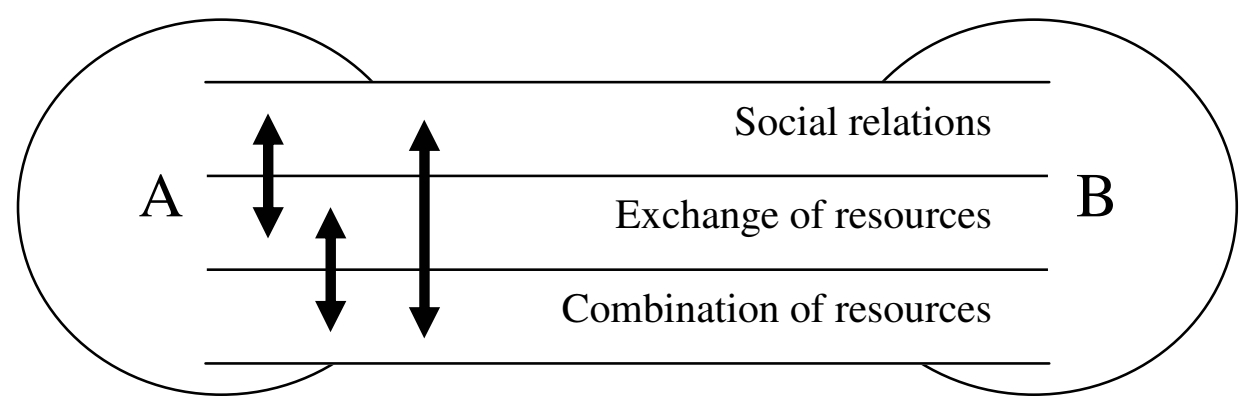

Figure 1. Relational Embeddedness

A high degree of relational embeddedness seems to be a crucial condition or at least a favored circumstance for finding and exploiting opportunities based on non-codified knowledge (see e.g. Hansen 1999). For instance, technology development research has analyzed the troublesome flow of complex knowledge, including non-codified knowledge, (Zander and Kogut 1995) and knowledge dependent on a larger system (Winter 1987). Further, the market as network perspective, mainly interested in activity relationships between firms, has rather emphasized the importance of close and interdependent relationships, especially in the case of product development (see e.g. Andersson and Forsgren, 1996, 2000; Håkansson 1989; Laage-Hellman 1989). The advantage of a high degree of relational embeddedness has also been observed by Uzzi (1997). He argues that a high degree of relational embeddedness enhances a flow of fine-grained knowledge between two firms and joint problem solving, while a low degree of relational embeddedness may cause problems in the flow of non-codified knowledge between firms. When exchange is strongly embedded in a technological structure and a set of social relations, the relationship tends to be characterized by extensive interaction, mutual trust, and relationship-specific advantage, which, in turn, means good knowledge about the counterpart. Finding technological opportunities, therefore, can be a result of solving problems that have occurred while interacting, and which, in turn, force the firms to cooperate to solve the problem. Altogether this means that changes concerning, for instance, exchange and technology, often are incremental and must fit into the present character of the relationship.

Hansen (1999) has shown that the advantage of relationships with a low degree of embeddedness as a source of opportunities prevails if the knowledge found is of a codified type. When the knowledge is of a non-codified complex type, there has to be a certain depth in the relationship, that is, a higher degree of relational embeddedness has its advantages when the firm exploits knowledge that originally resides in other relationships. Moreover, when the relationships are characterized by a high degree of relational embeddedness, firms tend to search for opportunities locally in their direct relationships. This corresponds to the idea that opportunities based on problem solving occur in a situation when the ends sought are defined but the means are still not defined (Ardichvili et al. 2003).

A high degree of relational embeddedness not only affects the opportunities found, but also influences how they are exploited. Relationships with a high degree of relational embeddedness are characterized by informal contracts, mutual trust and wide and intensive cooperation and interaction, where the exchange is dependent on social relations between people involved in the interaction and the combination of resources deployed in the technology. Therefore, changing the character of, for instance, the exchange of resources cannot be done autonomously from the social relations in the relationships. This makes exploitation of opportunities a more complicated process than in relationships with a low degree of embeddedness. Thus, exploitation of opportunities based on noncodified knowledge tends to be promoted by more deep and intense relationships between the firm and its counterparts, i.e. a high degree of relational embeddedness. This means that high degrees of 
embeddedness often promote technological opportunities, while relationships with low degrees of embeddedness tend to favor market opportunities. The reason for this is that technological opportunities usually contain a large element of non-codified knowledge (Andersson and Forsgren 1996, 2000; Andersson et al. 2001; Hansen, 1999; Håkansson 1989). Firms that share deep and intense relationships with each other are likely to possess more common knowledge of each other compared to actors which have relationships with a low degree of embeddedness. Moreover, a high degree of relational embeddedness means that the two firms are likely to develop a shared understanding of each others' capabilities and trustworthiness. A high degree of relational embeddedness can be viewed as the capacity of the relationship to hold knowledge that diminishes uncertainty (Granovetter 1973).

Moreover, a high degree of relational embeddedness implies a strong link between finding opportunities, which often is a result of problem solving or firms jointly searching for innovation, and exploitation. Finding and exploiting opportunities are, thus, integrated activities. The degree of embeddedness thus gives the relationship a certain structure that can be more or less dense, to put it simply. However, there is also reason to investigate the structure of the network to ascertain different bases needed for finding and exploiting opportunities with different characteristics.

\section{NETWORK STRUCTURE AS OPEN AND CLOSED SYSTEMS}

A common way to describe network structures is as open or closed systems (see e.g. Burt 1992a; Coleman 1990; Kogut 2000; Uzzi 1996;). The open network structure is the outcome of the competitive struggle between parties motivated by self-interest. The main construct in this type of network is the unique, i.e. non-redundant, relationship (Figure 2). A relationship is non-redundant if it is the only path between two actors. Thus, a completely open network consists only of non-redundant relationships, where there is only one path between the firms in the network (see Figure 2). This, in turn, means that open networks promote the flow of new knowledge, as it is less likely that a firm will receive the same knowledge from other counterparts.

Further, actors that have multiple non-redundant relationships to other actors who are not connected to each other have a strong brokerage position called "structural holes" (Burt 1992a). Firms positioned in structural holes have a more powerful position than others do because they control the knowledge flows between different networks (ibid.). Networks of this type tend to have a "hierarchical" structure although there are several hierarchies, and the firm bridging the structural holes earns the credit (Kogut 2000).

The closed network, on other hand, builds on the notion that firms in the network coordinate their efforts and actions (Figure 2). Coordination is improved through the continuous knowledge flows between the actors in the network (Coleman 1990). A closed network does not give the firms so much new knowledge because it is always likely that knowledge received from one counterpart will later be received from another counterpart as well. The redundant relationships between the network partners result in a resolution to collective action problems (Kogut 2000), but also allows the firm to check the quality of the knowledge and to reflect, compare and evaluate the received knowledge. 


\section{(A) Open network}

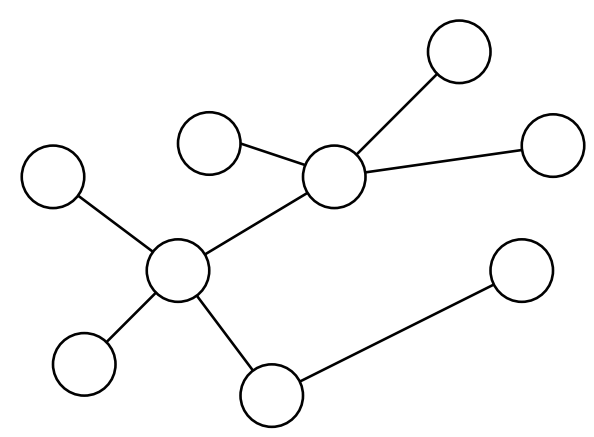

(B) Closed network

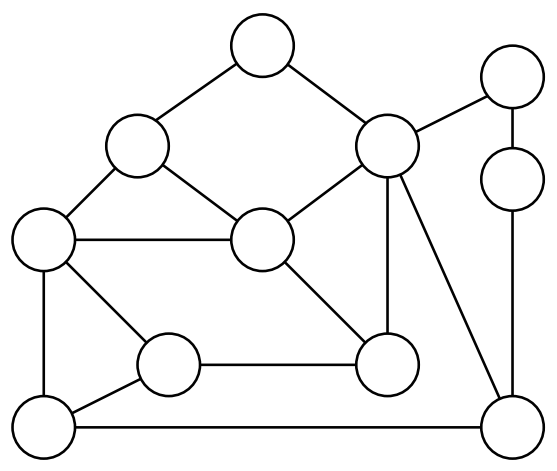

Figure 2. Open (A) and Closed (B) Networks

Network structure focuses on the position a firm occupies in the network beyond the immediate relationships. In these positional perspectives, the frame of reference shifts from the dyad or triad to the system. Different positions in a network have different advantages, e.g. a firm positioned between two other unconnected firms, which characterizes an open network, can control the knowledge flow between the other actors and thereby also influence the other actors' access to knowledge. (see e.g. Burt 1992a,b; Cook and Emerson 1978). Thereby, a completely open network gives each firm in the structure a possibility to control how and what knowledge is flowing through the network, which combined with the relatively large portion of new knowledge, makes it easy to keep critical knowledge (privileged knowledge) within the boundaries of the firm. But this is the same for all firms in the network.

On the other hand, we believe that a closed network causes technological opportunities, which are based on cooperation and coordination, but at the same time firms will find few market opportunities, as there is a limited flow of new knowledge inside the closed network. Thus, it is less likely that the opportunities will be characterized by novelty than in an open network. Therefore in an open network, joint search and learning is usually absent. But, on the other hand, the open network makes it possible for a firm to earn income based on its position in the network. Consider for example a situation, as in Figure 3, where the Firm $[A]$, has received new, and for some reason important, knowledge from its counterparts, $[B]$ and $[C]$. The Firm $[A]$ can now charge each of its other counterparts $[D]$ and $[E]$ arbitrage for supplying this knowledge, as they are not connected with each other or connected to any one else that can provide the knowledge except for firm [A]. This means that in open networks it is relatively easy to keep the benefits within the boundaries of the firm. In open networks, one can expect to see that firms, which find opportunities, strive to limit knowledge about them in order to fully exploit those opportunities, without sharing the benefits with other actors in the network.

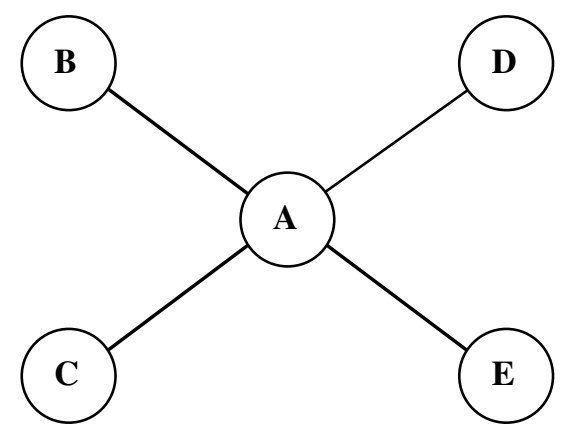

Figure 3. The rent accruing position in an open network 
In contrast to the broker earning credits in the open network, the closed network benefits the whole. The benefits of the closed network are not attributed to efficient flow of new knowledge, but rather to the fact that a large quantity of redundant relationships promotes cooperative behavior and coordination. Thereby the share of new knowledge in relation to the total amount of knowledge is smaller than in an open network (Burt 1992a). Although a more open network often provides a better structure for flow of new knowledge into and out of the network, it does at the same time give some actors a position to control the flow of knowledge in the network. The open network therefore tends to limit the reasons to cooperate and coordinate the actors' activities. Apparently closed and open networks both have their pros and cons when put in these absolute terms. To put it differently, given that the firm has a fixed amount of resources, if a firm has a relationship to counterpart $[A]$, which in turn has a relationship to $[B]$, it is better to relinquish a relation to $[B]$ and instead use the limited resources to engage in a new relationship with counterpart [C] (see the dotted lines in Figure 4). This is because the knowledge received from $[A]$ already contains the knowledge from $[B]$, as they are connected (Burt 1992a).

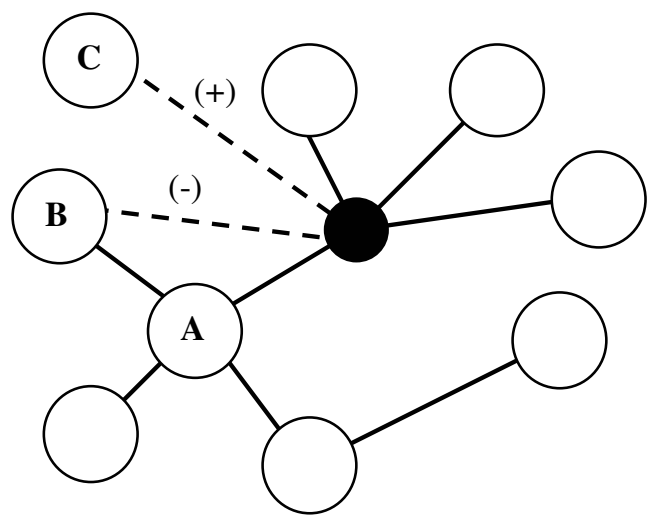

Figure 4. Rational use of limited resources in an open network according to Burt (1992a)

For instance, Uzzi (1997) argues that there is a risk of becoming locked-in in closed networks. It happens when the firms are too involved in too many relationships, which are connected with each other. In this network, there are few or no relationships with outside firms, who can potentially contribute new knowledge (Burt 1992a). A network, which is too closed, reduces the flow of new knowledge into the network, because it is likely that the same knowledge circulates in the network that the knowledge flowing is of the same character as that already used in the relationship. Extensive novelty is usually difficult to transform into incremental changes. Thus, we can conclude that an open network structure very much repeats the hierarchical structure, but in multiple ways, and that the benefits accrue to the bridging firm (Burt 1992a; Kogut 2000). On the other hand, a closed network facilitates a positive development of the whole network, through cooperation and coordination among the firms, where the gain is in being a part of the network structure.

\section{FINDING AND EXPLOITING OPPORTUNITIES}

Bringing together what is said above about relations, structures and opportunity, we can conclude that a firm's ability to find and exploit opportunities is dependent on its network structure, in terms of closure, as well as on the characteristics of its relationships, in terms of depth. Being embedded in a set of social relations and technological structures provides not only knowledge, resources, support and advice, but can also help the firm to find opportunities (Jack and Anderson 2002). 
This discussion reveals two contradicting forces influencing a firm's position to find opportunities and the configuration of the network and content of the relationships. First, there is the aspect of having sources, which provide new knowledge, which can be turned into opportunities. This seems to require that the firm has relationships with a low degree of embeddedness and that at least part of its network is open. Second, the firm's ability to absorb knowledge (Cohen and Levinthal 1990; Lane and Lubatkin 1998) and exploit those opportunities that are found is dependent on having relationships with a high degree of embeddedness and being in a position which enables cooperation and coordination with other actors, that is, being part of a closed network. This is because the more new knowledge of a non-codified type the opportunity contains, the greater the need for deep relationships in order for the firm to have good possibilities to assimilate the knowledge. Based on the discussion above, we are then facing four theoretical situations, summarized in Figure 5 . These theoretical situations are by no means situations commonly found in reality but rather archetypes helping to clarify the subsequent discussion.

Network Structure

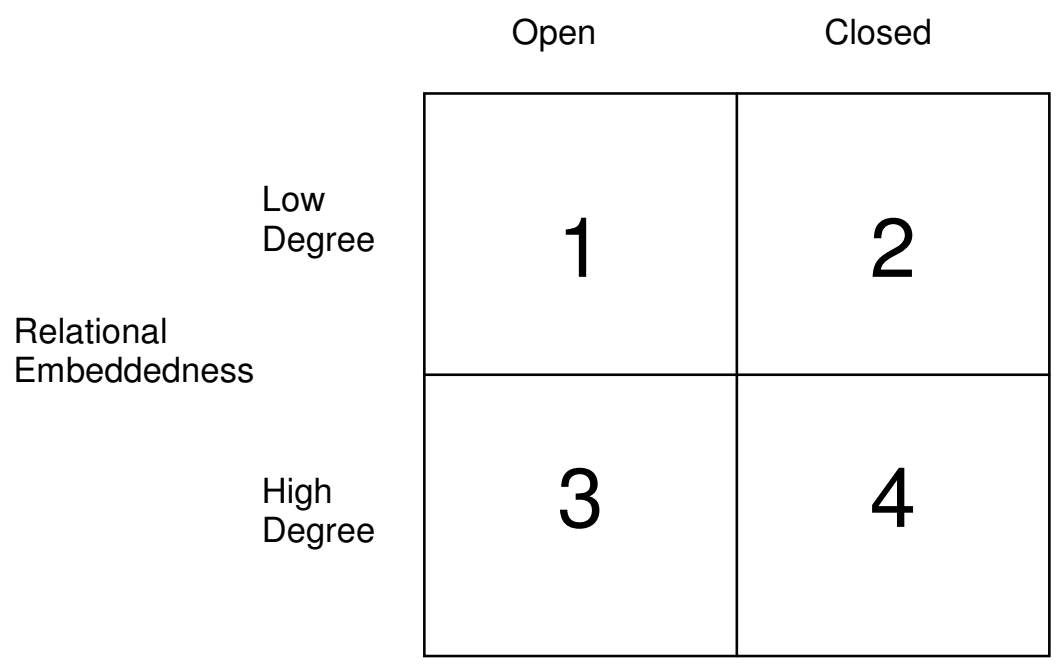

Figure 5. Impact on finding and exploiting opportunities by embeddedness and network structure

The theoretical situations are:

1) an open network with a low degree of embeddedness, 2) a closed network with a low degree of embeddedness, 3) an open network with a high degree of embeddedness, and 4) a closed network with high degree of embeddedness. These four situations will be further discussed below.

\section{AN OPEN NETWORK WITH LOW DEGREE OF RELATIONAL EMBEDDEDNESS}

If we first of all consider the critical issue of knowledge as a source of opportunity, the possibilities for the firm to receive new knowledge increases if the firm has relationships to many counterparts that can provide such knowledge. From a structural point of view, this is the case when the firm's relationships are unrelated to each other, i.e. cell 1 in Figure 5. In an open structure (Burt 1992a), the probability of each counterpart contributing unique knowledge increases, as the firms are not connected to each other. Moreover, when an open network contains relationships with a low degree of relational embeddedness as shown in Figure 6, it seems likely to expect that the firm is in a good position to find opportunities if they are based on knowledge that is codified.

Thus, this situation implies that the opportunities found will be based on a large proportion of new, but codified knowledge. Such a situation also tends to be a good basis for finding market opportunities, 
while finding and exploiting technological opportunities is less likely. The reason for this is that assimilation of opportunities based on non-codified knowledge is difficult, thus, the more the knowledge is of a non-codified kind, the more difficult it is to assimilate the opportunities.

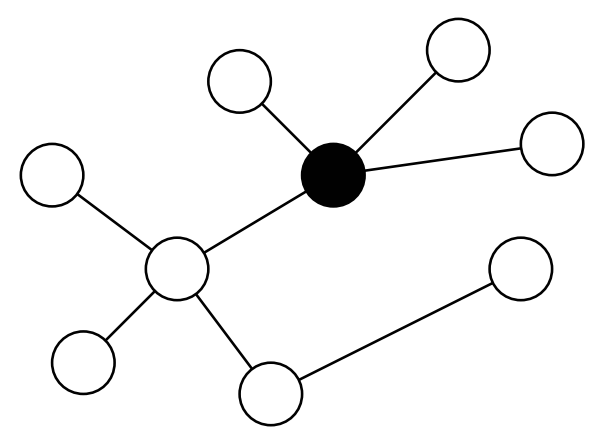

Figure 6. An open network with a low degree of relational embeddedness

We have reason to assume that the coordination and cooperation that is needed for integration of more complex knowledge is difficult to achieve as the relationships are not connected and therefore lack a common knowledge base (Cohen and Levinthal 1990; Coleman 1990; Lane and Lubatkin 1998). Another characteristic of this type of situation is that the firm in focus can relatively easily earn income at the expense of other firms (see Burt 1992a; Kogut 2000), as it can keep critical knowledge inside the firm and not let other firms, with which it has relationships, know about the exploitation of the opportunity.

This observation has much in common with what a stockbroker does. By connecting buyers and sellers of different stocks, having a position such as the firm portrayed in black in Figure 6 is beneficial. For a stockbroker, the only crucial knowledge needed is who wants to sell a particular stock and who wants to buy that stock. By being the connecting link between the buyers and sellers, the brokerage firm earns income. The minute there is a direct relation between the buyer and the seller they can commence the deal without having to pay extra for the knowledge of the potential buyer or seller residing in the brokerage firm. Also, the stockbroker does not benefit to any large extent by adapting and learning more about its selling counterpart, price and quantity is sufficient to conduct a deal. Opportunities arise as the broker has a matching pair of buyers and sellers, in fact business and opportunity is very much the same thing in this example.

We summarize the above discussion by formulating the following propositions:

P1: Firms operating in an open network structure with a low degree of relational embeddedness are likely to find market opportunities based on codified and new knowledge.

P2: Firms finding market opportunities in an open network structure with a low degree of relational embeddedness are likely to earn payment from exploitation of the opportunities.

\section{A CLOSED NETWORK WITH LOW DEGREE OF RELATIONAL EMBEDDEDNESS}

However, we can also imagine a situation, which corresponds to cell 2 in the matrix (i.e. Figure 5), where there is a closed network with a low degree of relational embeddedness. 


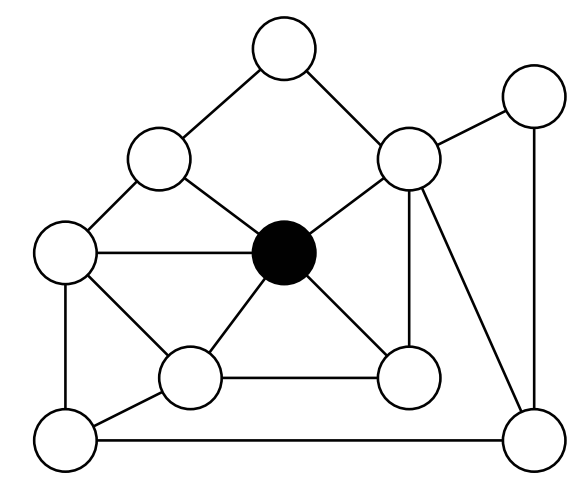

Figure 7. A closed network with a low degree of relational embeddedness

In such a system, we have reason to anticipate that there is more coordination and cooperation between the firms in the network than in the previous situation, where the network had an open structure (Coleman 1990; Kogut 2000). But this situation can provide difficulties for the firm. On the one hand, the closed structure in the network increases the possibility for finding and exploiting technological opportunities, as this type of structure imposes a similar knowledge base on the firms (Cohen and Levinthal 1990; Lane and Lubatkin 1998). On the other hand, it is likely that the low degree of relational embeddedness and the closed network tend to give the firm advantageous search options if knowledge is codified, which means that assimilation based on non-codified knowledge is difficult. Opportunities tend in this situation to be based on existing knowledge. Finally, it seems that this structure does not allow the firm to make arbitrary profits at the other firms' expense, as is the case in the open structure in Figure 6, as the need for cooperation means that benefits are shared. Thus, we let proposition 5 to 9 summarize some of the recognized conditions in this situation.

P3: Firms operating in a closed network structure with a low degree of relational embeddedness are likely to find market opportunities based on codified and existing knowledge.

P4: Firms finding market opportunities in a closed network structure with a low degree of relational embeddedness are likely to share the benefits from exploitation of the opportunities with other firms in the network.

It seems that this structure is not a very common one in real life, at least not for long periods of time. To some extent this structure can be found in the clothing industry where a designer in a particular country sends patterns to tailors in countries where labor-intensive tasks are cheaper. At the same time the designer orders a specific fabric from firms in maybe several other countries. The fabric is directly shipped to the tailors who, for instance, manufacture a certain type of jacket. At the same time, advertising firms in the end markets prepare the advertising campaigns. When the jacket is finished it is shipped directly by a transportation company to the countries where it is sold in stores. The tailors get a specific amount of jackets to be sewn depending on their spare capacity at that particular time and it is also easy to imagine that the tailors back up each other and change the original order from the designer. As long as the end result is the same the designer has, probably, no opinion about who has actually manufactured the jacket. It is also easy to imagine how several stores or outlets in the same region or country cooperate to get cheaper shipment by sharing the same distributor. In this example, opportunities appear when quantities or prices are changed for some reason and are ended by the flexibility and information processing speed of the involved firms.

\section{AN OPEN NETWORK WITH HIGH DEGREE OF RELATIONAL EMBEDDEDNESS}

An almost opposite situation is illustrated by cell 3 in Figure 5 . Here, an open network surrounds the firm with a high degree of relational embeddedness. This is a complicated situation, because a high 
degree of relational embeddedness and an open network represent to some extent contradictory forces. One the one hand, a high degree of relational embeddedness promotes acquisition of complex knowledge and joint problem solving while an open network means a possibility to control knowledge flows and to acquire codified knowledge.

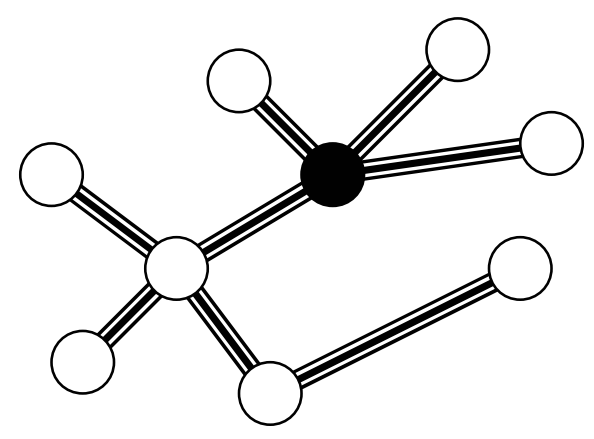

Figure 8. An open network with a high degree of relational embeddedness

We expect that much of what typifies the opportunities in this situation is based on how the firm cooperates with its counterparts, which especially concerns exploitation of opportunities, since the relational embeddedness means good conditions to assimilate complex and non-codified knowledge. The fact that the firm has only one path to all the other firms in the network means that much of the knowledge that travels through the network is new. This seems to promote technological opportunity. Exploitation of opportunities in this situation usually takes place within the boundaries of the firm or in dyadic relationships and mostly concerns integration of the firms' activities and resources. This is, for instance, the case in the running operations in the car manufacturing industry, where there are strong and deep relationships between different actors, but where the network to a large extent consists of a set of separate relationships and where technical development is a continuous activity. There is also much adaptation between the involved firms concerning logistics and administrative systems in order to accomplish just-in-time deliveries and lean and efficient production.

The network gives each firm a possibility to keep that knowledge within the firm and to earn revenue from exploitation of that knowledge as long as the firm has power in relation to its counterpart. The situation resembles a value chain (Porter 1986) or a distribution channel (see El-Ansary and Stern 1972; Gaski 1984; Hunt and Nevin 1974) where power and control are sources to earn profits and where conflict between the firms in the dyadic relationship are likely as the high degree of relational embeddedness gives the firm good insight in the counterparts' operations.

However, the high degree of relational embeddedness can force the firm to share the benefits with some specific counterparts, since it is likely that, due to the high degree of relational embeddedness, it is able to fully exploit the opportunities. But this situation also gives rise to another type of opportunities, which are based on dyadic cooperation, joint learning and not on the flow of knowledge in the network. If that is the case, there are good possibilities to keep the knowledge within the boundaries of specific relationships and to assure that it is not spread.

P5: Firms operating in an open network structure with a high degree of relational embeddedness are likely to find technological opportunities based on non-codified and new knowledge.

P6: Firms finding technological opportunities in an open network structure with a high degree of relational embeddedness are likely to earn profits from exploitation of the opportunities. 
However, this view of the network is maybe too simple, in the sense that the role of the firm is not only to absorb new knowledge. The firm's role is also to participate in a development process, which includes several actors. The following proposition is seen as an important consequence to be handled by management to see that the firm does not loose the advantage from opportunities created by receiving new and non-codified knowledge.

P7: An open network with a high degree of embeddedness will force the firm to carefully choose among counterparts when it comes to deepen the cooperation and coordination.

\section{CLOSED NETWORK WITH HIGH DEGREE OF RELATIONAL EMBEDDEDNESS}

In the situation portrayed in Figure 9, the firm has strong and tight relationships to its business partners, i.e. a closed network structure. As the relational embeddedness is high, cooperation and coordination of activities is deep, which implies that the possibilities for technological opportunities are good, but there is a risk of receiving mostly existing knowledge through the different relationships. This is the case when an actor is connected to other actors, which in their turn are connected with each other, the actor is locked in and receives existing knowledge.

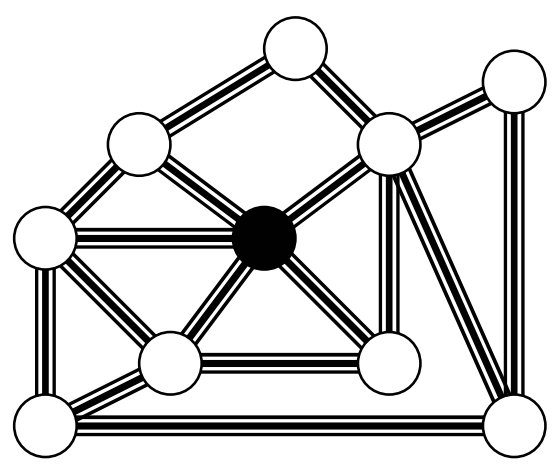

Figure 9. A closed network with a high degree of relational embeddedness

On the other hand, this situation gives the firm a good position to compare the existing knowledge with the little new knowledge, which pours into the network. Through repetition and reflection, firms can check the content and quality of the new knowledge and together with other firms jointly solve problems. In such a process, the problem is not to find the one missing piece in the puzzle, it is rather to learn and understand how to modify your own puzzle to better fit the other actors' puzzles. In such a situation where learning complex knowledge is important, the high degree of relational embeddedness and networks with strong connectivity are clearly superior (Coleman 1990; Hansen 1999; Kogut, 2000). This means that most opportunities are a result of joint learning in the network, which, in turn, has effects on how the benefits of the opportunity found are later exploited. Since finding the opportunity is a result of joint efforts and cooperation it is difficult for a single firm in the network not to share the benefits with other actors. Instead, a high degree of relational embeddedness and the closed network structure tend to distribute the fruits more evenly over the network than in the other three situations discussed. As there is a risk for inbreeding in this situation, firms will have to look for ties that might give new inputs and opportunities.

This type of network is time-limited in one way or another; it perfectly portrays a firm that is overembedded in Uzzi's (1997) terms. A situation where this form of network does appear is in large, technically advanced projects like developing a new fighter jet, for instance. All included sub systems and materials are developed at the edge of their technical capabilities, and often even in advance of this, adaptation between all or most of the involved firms is crucial to the success of the project. Opportunities occur in the intersection between different subsystems and their development, meaning 
that the development in one system forces or opens up for development and changes in another subsystem. At the same time these joint developments of two of the included subsystems affect a third and require changes to it, and so on. Much of the development and opportunities happen when the firms involved solve problems together. Much of the exploitation of the opportunities comes about when the whole system (the fighter jet) is delivered, but also after completion of the project when each firm tries to exploit it's learning by applying the developments in different networks. This can be summarized by the following propositions:

P8: Firms operating in a closed network structure with a high degree of relational embeddedness are likely to find technological opportunities based on non-codified and new knowledge.

P9: Firms finding technological opportunities in a closed network structure with a high degree of relational embeddedness are likely to share the benefits from exploitation of the opportunities with other firms in the network.

P10: A closed network with a high degree of relational embeddedness is only likely to exist for a limited time.

\section{FINAL DISCUSSION}

The pros and cons of closed and open networks and high or low degrees of relational embeddedness depend on the specific situation. The more the firm's network contains intense and deep relationships, i.e. a high degree of relational embeddedness, the larger the extent that its opportunities are founded on complex knowledge. If the network configuration is also of a closed type we can expect that the exploitation of these opportunities will be facilitated by the cooperative and coordinative character such networks have. On the other hand, new knowledge is more easily accessed in a network of many unconnected participants having relations with a low degree of embeddedness to each other. In such a network the firm detecting the opportunity also has a better possibility to keep the knowledge inside the firm and can earn profit during the exploitation phase.

It is in a sense difficult to imagine any firm being situated in any of the above-mentioned 'ideal' situations; in reality a firm has relationships characterized by both high and low degrees of embeddedness. Likewise, no system, i.e. network, is totally open or totally closed, even if parts of the system could reflect such a homogenous character. One important conclusion from the reasoning above ought to be that an ideal network should contain relationships of varying degrees of embeddedness and be of a semi- open/closed structure to ensure survival of the firm in the long run.

Extending the boundaries of the studied network will reveal different and even contradictory results from the reasoning above. It is important in this chapter to remember that we are dealing with 'ideal types' to be able to draw conclusions and that the archetypes developed seldom appear in real life. For example, think of a firm producing goods. Figure 10 shows a plausible picture of how this firm's network may look, in terms of relational embeddedness and network structure. 


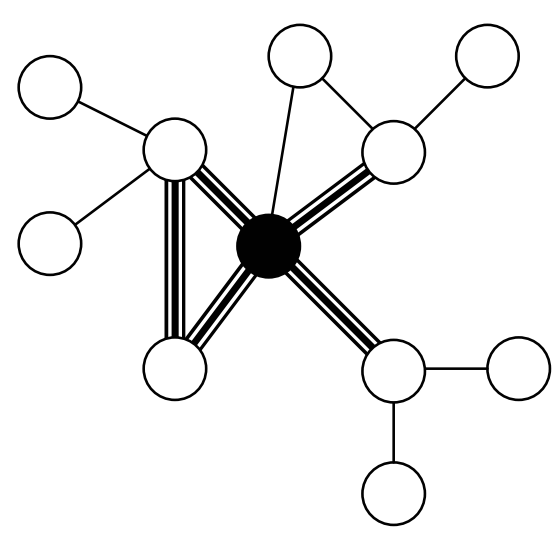

Figure 10. A semi-open network with different degrees of relational embeddedness

Viewing Figure 10 from left to right we can think of suppliers in the left end and customers in the right end of the figure. The firm's direct relationships are of a relatively high degree of embeddedness while its connected relations are of a more low degree of embeddedness. Further the firm's network contains both closed and open structures depending on where we draw the line of inquiry. It is easy to see how new knowledge enters the central parts of the network depicted in Figure 10 from different unconnected actors having relations with low degrees of embeddedness. It is also straightforward to understand the preconditions for problem solving processes in the highly embedded relationships between the firm and its customers, allowing knowledge of a more complex and fine-grained type to flow between the parties. It is further, rather easy to depict how the "triad" of firm and suppliers develop together as the structure in which they pursue their activities fosters coordination and cooperation.

Summarizing the idea of this chapter would be to say that optimal findings and exploitation of opportunities are recognized to have different prerequisites. These are manifested through the network thus showing the different roles that the network has from a market as well as technological aspect.

As the concept of a network is getting more and more used in business research, it is important to conclude from this chapter that a network is not always the same thing. It differs in closure as well as in the depth and intensity of the relationships. If network as a concept is used in business research it should be thoroughly defined in terms of the characteristics brought up in this chapter. As is evident from our discussions, the characteristics of the network, in terms of relational embeddedness and closure, have very different implications for how firms find and exploit opportunities.

Further, we can see that the impact of relational embeddedness on the firm's possibilities of finding and exploiting opportunities is dependent on whether the network is closed or open; also that the influence the network structure has on the firm's possibilities of finding and exploiting opportunities is dependent on the degree of relational embeddedness it has with its network partners. Taken together this means that a lot more research is needed in order to fully expose how network structures and relationship characteristics influence opportunities. 


\section{REFERENCES}

Andersson, Ulf and Mats Forsgren (1996), Subsidiary Embeddedness and Control in the Multinational Corporation, International Business Review, 5/5, 487-508.

--- and --- (2000), In Search of Centre of Excellence: Network Embeddedness and Subsidiary Roles in Multinational Corporations, Management International Review, 40/4, 329-350.

---, --- and Torben Pedersen (2001), Business Enterprise Performance in MNCs: The Importance of Technology Embeddedness, International Business Review, 10/1, 3 - 23.

Ardichvili, A., Cardozo, R. and Ray, S. (2003). A Theory of Entrepreneurial Opportunity Identification and Development, Journal of Business Venturing, 18/1, 105-123.

Burt, Ronald (1992a), Structural Holes: The Social Structure of Competition. Cambridge, MA: Harvard University Press.

--- (1992b), The Social Structure of Competition. In N. Nohria and R. Eccles (eds.) Networks and Organizations. Structure, Form and Action, Cambridge, MA: Harvard Business School Press.

Casson, Mark (1982), The Entrepreneur, Totowa, NJ: Barnes and Noble Books.

Choi, Y. R. and Shephard, D. A. (2004). Entrepreneurs Decisions to Exploit Opportunities, Journal of Management, 30/3, 377-395.

Cohen, W. and Daniel A. Levinthal (1990), Absorptive Capacity: A New Perspective on Learning and Innovation, Administrative Science Quarterly, 35/1, 128-152.

Coleman, J. (1990), Foundations of Social Theory. Cambridge, MA: Harvard University Press.

Cook, K. S. and Emerson, R. M. (1978). Power, Equity and Commitment in Exchange Networks, American Sociological Review, 43, 721-738.

Dyer, Jeffrey H. and Chu, W. (2000), The Determinants of Trust in Supplier-Automaker Relationships in the U.S., Japan, and Korea. Journal of International Business Studies, 31/2, 259-285.

Eckhardt, J. T. and Shane, S. A. (2003), Opportunities and Entrepreneurship, Journal of Management, 29/3, 333-349.

El-Ansary, A. I. and Stern L. W. (1972), Power Measurement in the Distribution Channel, Journal of Marketing Research, 9/1, 47-52.

Ellis, P. (2000), Social Ties and Foreign Market Entry, Journal of International Business Studies, 31/3, 443-469

Ford, David, Lars-Erik Gadde,, Håkan Håkansson and Ivan Snehota (2003), Managing Business Relationships. Chichester: Wiley.

Gaski, J. F. (1984), The Theory of Power and Conflicts in Channels of Distribution, Journal of Marketing, Vol. 48 Summer, pp. 9-29.

Grabher, Gernot (1993), Rediscovering the Social in the Economics of Interfirm Relations. In G. Grabher (ed.), The Embedded Firm, London, Routledge.

Granovetter, Mark (1973),. The Strength of Weak Ties, American Journal of Sociology, 78/6, 13601380.

--- (1985), Economic Action and Social Structure: The Problem of Embeddedness, American Journal of Sociology, 91/3, 481-510. 
--- (1992), Problems of Explanation in Economic Sociology. In Nohria and Eccles (eds.), Networks and organizations: Structure, form and action. Boston: Harvard Business School Press.

Gulati, R. (1998). Alliances and Networks, Strategic Management Journal, 19/4, 293-318.

--- (1999). Network Location and Learning: The Influence of Network Resources and Firm Capabilities on Alliance Formation, Strategic Management Journal, 20/5, 397-420.

---, Nitin Nohria and A Zaheer (2000), Strategic Networks. Strategic Management Journal, 21/3, 203215.

Halinen, Aino and Törnroos, Jan- Åke (1998), The Role of Embeddedness in the Evolution of Business Networks. Scandinavian Journal of Management, 14/3, 187-205.

Hansen, Morten T. (1999), The Search-transfer Problem: The Role of Weak Ties in Sharing Knowledge across Organization Subunits. Administrative Science Quarterly, 44/1, 82-111.

Hayek, F. A. (1945). The Use of Knowledge in Society, American Economic Review, 35/4, 519-530.

Hunt, S. D. and J. R. Nevin (1974), Power in a Channel of Distribution: Sources and Consequences, Journal of Marketing Research, Vol. 11 May, 186-93.

Håkansson, Håkan (ed.), (1982), International Marketing and Purchasing: An Interaction Approach. Chichester: John Wiley and Sons.

--- (1989), Corporate Technological Behaviour: Co-operation and Networks. London: Routledge.

--- and Ivan Snehota (1995), Developing Relationships in Business Networks. London: Routledge.

Jack, S. L. and A. Anderson (2002), The Effects of Embeddedness on the Entrepreneurial Process, Journal of Business Venturing, 17/5, 467-487.

Kenney, M. and W. R. Goe (2004), The Role of Social Embeddedness in Professorial Entrepreneurship: A Comparison of Electrical Engineering and Computer Science at UC Berkeley and Stanford, Research Policy, 33/5, 691-707.

Kirzner, Israel M. (1973), Competition \& Entrepreneurship. Chicago: University of Chicago Press.

--- (1992), The Meaning of Market Process: Essays in the Development of Modern Austrian Economics. London: Routledge.

--- (1997). Entrepreneurial Discovery and the Competitive Market Process: An Austrian Approach, Journal of Economic Literature, 35/1, 60-85.

Kogut, Bruce (2000), The Network as Knowledge: Generative Rules and the Emergence of Structure, Strategic Management Journal, 21/3, 405-425.

Laage-Hellman, Jens (1989),. Technological Development in Industrial Networks. Ph.D. Dissertation, Uppsala, Acta Universitatis Upsaliensis.

Lane, Peter J. and Michael Lubatkin (1998), Relative Absorptive Capacity and Internorganizational Learning. Strategic Management Journal, 19/5, 461-477.

March, James G. (1991), Exploration and Exploitation in Organizational Learning. Organization Science, 2/1, 71-87.

McEvily, B. and A. Zaheer (1999), Bridging Ties: A Source of Firm Heterogeneity in Competitive Capabilities, Strategic Management Journal, 20/12, 1133-1156.

Porter, Michael E. (1986), Competition in Global Industries. Boston, Harvard Business School Press. 
Rowley, T., D. Behrens and D. Krackhardt (2000), Redundant Governance Structures: An Analysis of Structural and Relational Embeddedness in Steel and Semiconductor Industries, Strategic Management Journal, 21/3, 369-386.

Schumpeter, J. (1934),. Theory of Economic Development, Cambridge, MA, Harvard University Press.

Shane, S. (2000). Prior Knowledge and the Discovery of Entrepreneurial Opportunities, Organization Science, 11/4, 448-469.

Simsek, Z., Michael H. Lubatkin and S. W. Floyd (2003), Inter-Firm Networks and Entrepreneurial Behavior: A Structural Embeddedness Perspective, Journal of Management, 29/3, 427-442.

Uzzi, Brian (1996), The Sources and Consequences of Embeddedness for Economic Performance of Organizations: The Network Effect, American Sociological Review, 61/4, 674-698.

--- (1997), Social Structure and Competition in Interfirm Networks: The Paradox of Embeddedness, Administrative Science Quarterly, 42/1, 35-67.

Winter, Sidney (1987), Knowledge and competence as strategic assets. In D. Teece (ed.), The Competitive Challenge - Strategies for Industrial Innovation and Renewal, Cambridge, MA.: Ballinger.

Zander, Udo and Bruce Kogut (1995), Knowledge and the Speed of Transfer and Imitation of Organizational Capabilities: An Empirical Test', Organization Science, 6/1, 76-92.

Zukin, S. and Paul J. Di Maggio (Eds.), (1990), Structure of Capital, Cambridge, Cambridge University Press. 